\title{
Senology in Gynaecology Specialist Training: a Baseline Survey from 2014
}

\author{
Senologische Weiterbildung in der Gynäkologie: eine Bestandsaufnahme 2014
}

Authors

Affiliations
J. Puppe ${ }^{1}$, M. Dieterich ${ }^{2}$, C. Bayer ${ }^{3}$, J. Neiman ${ }^{4}$, M. de Sousa Mendes ${ }^{5}$, P. Gaß ${ }^{3}$, J. Lermann ${ }^{3}$, S. Schott ${ }^{6}$

The affiliations are listed at the end of the article.

\begin{abstract}
Key words
- training in senology

- gynaecology

- DGGG Young Forum

- speciality training

Schlüsselwörter

- Weiterbildung Senologie

- Gynäkologie

- Junges Forum der DGGG

- Facharztweiterbildung
\end{abstract}

Deutsche Version unter: http://dx.doi.org/ $10.1055 / \mathrm{s}-0042-104055$

$\begin{array}{ll}\text { received } & 1.9 .2015 \\ \text { revised } & 26.1 .2016 \\ \text { accepted } & 28.2 .2016\end{array}$

Bibliography

DOI http://dx.doi.org/

10.1055/s-0042-104055

Geburtsh Frauenheilk 2016; 76:

564-569 ๑ Georg Thieme

Verlag KG Stuttgart · New York. ISSN 0016-5751

\section{Correspondence}

Dr. med. Julian Puppe

Uniklinik Köln

Klinik und Poliklinik für Frauenheilkunde und Geburtshilfe

Kerpener Straße 34

50931 Köln

Julian.puppe@uk-koeln.de

\section{Abstract \\ $\nabla$}

Introduction: Qualified training in senology is essential for maintaining adequate, high quality patient care. In order to meet the needs of doctors in training and those of the medical infrastructure it is necessary to assess the quality of training regularly, to enable its adaption and optimisation.

Methods: We developed a comprehensive, 10 item online questionnaire to assess the quality of specialised training in senology. This questionnaire was sent to 4000 speciality trainees and young specialists countrywide via the DGGG newsletter and was accessible for over four weeks.

Results: 111 obstetrics and gynaecology speciality trainees participated in this national survey, $79 \%$ of whom were female. $33 \%$ of participants were working at university hospitals, $29 \%$ at hospitals offering maximal level care without an associated medical faculty, $37 \%$ at hospitals offering primary and secondary level care and $2 \%$ at gynaecology practices. $25 \%$ of participants could imagine working in the field of senology in future. On average the current perception of general specialist training was satisfactory. Specialist trainees at university hospitals rated training in senology highest (score: 2.95) compared to those at other hospitals. A fixed rotation through a breast centre offering comprehensive advanced training was seen as a potential improvement to senology training.

Conclusions: This is the first survey of specialised training in senology to be conducted in Germany. Results showed that there is significant potential for young doctors to enter the speciality in future. There are also significant differences in the perceived quality of senology training between training facilities. This survey aimed to determine the quality of specialised training at senology centres and hopes to contribute to a sustainable improvement in training. The intention is to continue to

\section{Zusammenfassung \\ $\nabla$}

Einleitung: Eine qualifizierte Weiterbildung in der Senologie ist für das Fortbestehen einer guten und qualitativ hochwertigen Patientenversorgung essenziell. Um den Ansprüchen der Weiterbildungsassistenten und der medizinischen Infrastruktur gerecht zu werden, ist es notwendig, die Weiterbildungsqualität regelmäßig zu erfassen, um diese entsprechend anpassen und optimieren zu können.

Methodik: Zur Erfassung der Weiterbildungsqualität haben wir einen 10 Items umfassenden Online-Fragebogen entwickelt. Die bundesweite Umfrage wurde an 4000 Assistenten und junge Fachärzte über den Newsletter der DGGG adressiert und war über 4 Wochen lang zugängig. Ergebnisse: An der Umfrage nahmen 111 Weiterbildungsassistenten aus der Gynäkologie und Geburtshilfe teil, davon $79 \%$ weiblich. 33\% der Befragten arbeiteten an einer Universitätsklinik, 29\% an einem Haus der Maximalversorgung ohne medizinische Fakultät, 37\% an einem Krankenhaus der Grund- und Regelversorgung sowie 2\% in einer Niederlassung. Eine zukünftige berufliche Betätigung im Bereich der Senologie konnten sich $25 \%$ der Befragten vorstellen. Die aktuell wahrgenommene allgemeine Weiterbildungsqualität wurde durchschnittlich als befriedigend bewertet. Die senologische Weiterbildung wurde von Weiterbildungsassistenten an Universitätskliniken im Vergleich zu Häusern der Maximal-, Grund- und Regelversorgung am besten bewertet (Note: 2,95). Eine Verbesserungsmöglichkeit der senologischen Weiterbildung wurde in einer festen Rotation in ein Brustzentrum mit umfassenden Fortbildungsmöglichkeiten gesehen.

Zusammenfassung: Es handelt sich um die erste Bestandsaufnahme zur senologischen Weiterbildung in Deutschland. Die Ergebnisse zeigen, dass es großen potenziellen Nachwuchs gibt. Des Weiteren existieren große Unterschiede in der emp- 
make senology attractive to gynaecologists and to ensure wellgrounded training. fundenen Weiterbildungsqualität zwischen den Weiterbildungsstätten. Diese Umfrage soll dazu beitragen, die Weiterbildungsqualität an senologischen Zentren für Assistenten der Gynäkologie und Geburtshilfe zu erfassen und nachhaltig zu verbessern. Ziel ist es, die Senologie weiterhin für Gynäkologen attraktiv zu gestalten und eine solide Weiterbildung sicherzustellen.

\section{Introduction \\ $\nabla$}

Senology has an established place in gynaecological oncology care in Germany [1]. The diagnosis, treatment and follow-up of diseases of the female breast (senology/mastology) is an interdisciplinary field involving gynaecology, radiology, pathology and other specialities. The German Association of Senology (Deutsche Gesellschaft für Senologie e.V., DGS) was founded under gynaecological leadership in 1981 in order to optimise the interdisciplinary management of breast diseases. Gynaecologists continue to form the largest speciality group within the organisation with a representation of $47 \%$ [2].

Training in senology is covered in the accreditation rules for specialist training in obstetrics and gynaecology. The German medical council does not recognise or offer a senology subspeciality or special interest qualification. On the contrary, young doctors must attend additional training events such as courses offered by the German Academy of Senology [3] to acquire basic knowledge and further qualification in the field. A compounding factor is that the full spectrum of subject matter in senology, and thus the possibility of specialised training, is almost exclusively offered in breast centres and maximal level care facilities [4]. Due to this concentration of care in larger centres the majority of specialist trainees does not have access to comprehensive further training in senology in routine clinical practice. Some practices accredited for specialist training do offer exposure to aspects of senology and associated learning opportunities, however such concepts within structured rotations are limited to a few regions. Thus, in 2014, the German Academy of Senology created a specific interdisciplinary curriculum [3].

The provision of adequate, practice oriented training in senology for young doctors is imperative to maintain the high quality standards of existing senology care structures into the future. To ensure continual improvement of training it is essential to record the experiences of trainees and consider how they rate their training. To date there have been no studies evaluating the quality of further training in senology. The aim of this nationwide survey by the Young Forum of the German Association of Obstetrics and Gynaecology (DGGG e.V.) was therefore to produce baseline data on senology training as it is in practice, and to document how this training is perceived by specialist trainees. In addition structured training concepts in hospitals and breast centres were sought. Further aims of this online survey were to contribute to improved knowledge of the needs and demands of young doctors and make suggestions for improved training content.

\section{Methods \\ $\nabla$}

\section{Recruitment}

An online questionnaire comprising 10 items was developed by the working group of the DGGG Young Forum and distributed to over 4000 doctors in specialist and subspecialist training via the Young Forum's newsletter. Data collection was performed in June
2014 over a period of 4 weeks. There were 111 participants in total (participation rate: $2.8 \%$ ). Anonymised data analysis was performed using the www.surveymonkey.com software tool. An anonymous IP address check was conducted to avoid multiple participations.

\section{Questionnaire}

The first part of the questionnaire covered basic data including sex, demographics (e.g. age) and career details (year of speciality training, training location). The questionnaire further explored young doctors' interest in senology training and the quality of training. Distinction was made between hospitals providing routine primary and secondary level care, those offering maximum level care, and university hospitals. Doctors were also questioned on important aspects of training content and quality indicators. Unless otherwise stated questions could be rated from 1-6, with 1 the best and 6 the worst possible ratings (very important - not important at all). The average score was established in each case with ratings from 1-3 considered supportive answers.

\section{Statistics}

Statistical analysis of the results was performed using Excel 2011 software, with unpaired t-tests and normally distributed samples (significance level: $\mathrm{p}<0.05$ ).

\section{Results}

$\nabla$

Demographics and work experience of participants

There were 111 study participants in the four-week-long survey of whom $79.3 \%(n=88)$ were female. The average age of participants was 31.8 years. The majority (33\%) were in their 5 th year of specialist training and $99 \%$ were employed in the hospital setting ( Fig. 1). At only $1 \%$, medical centres and practices were underrepresented and thus were excluded from the further analysis.

\section{Senology as a career aim: Potential for young blood}

$25 \%$ of participants could imagine working in the field of senology in future, whereas $31 \%$ did not wish to. $44 \%$ did not yet know (॰ Fig. 2).

\section{Quality of training: Substantial differences between} university hospitals and smaller training facilities Overall, participants rated their training in senology as satisfactory (score 3.34). Satisfaction was highest among specialist trainees at university hospitals, with those in primary and maximum care hospitals without university faculties rating their training somewhat worse ( Table 1 ).

- Fig. 3 shows the evaluation of current training quality in the different areas of senology. Tertiary level, university-associated centres had the best scores in all areas covered. Overall, training was rated best in breast surgery (mean score: 2.88 ). Compared to university hospitals, training in other facilities (non-university hospitals) was rated particularly badly in medical tumour treat- 


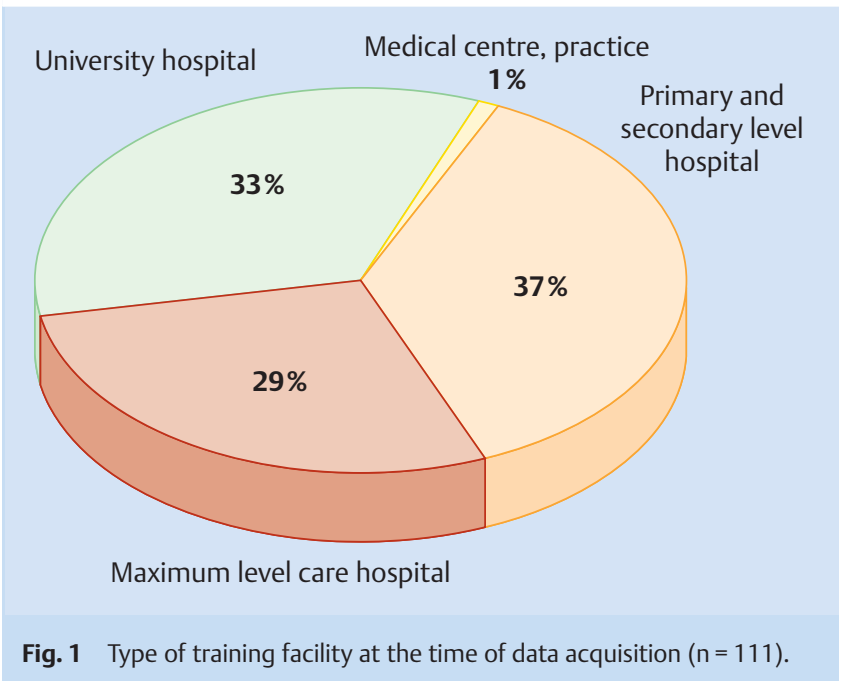

ment/therapeutics (university hospitals [1.92] vs. primary and secondary level hospitals [3.56] or maximum level care hospitals [3.29]) and plastic/reconstructive breast surgery (university hospitals [2.70] vs. primary and secondary level hospitals [3.91] or maximum level care hospitals [4.00]). Training towards a career in academics was also best at university hospitals (university hospitals [3.05] vs. primary and secondary level hospitals [4.65] or maximum level care hospitals [4.32]). The difference was significant in each case $(\mathrm{p}<0.001)$. Young gynaecology trainees criticised training in radiation therapy and pyschooncology at all facilities.

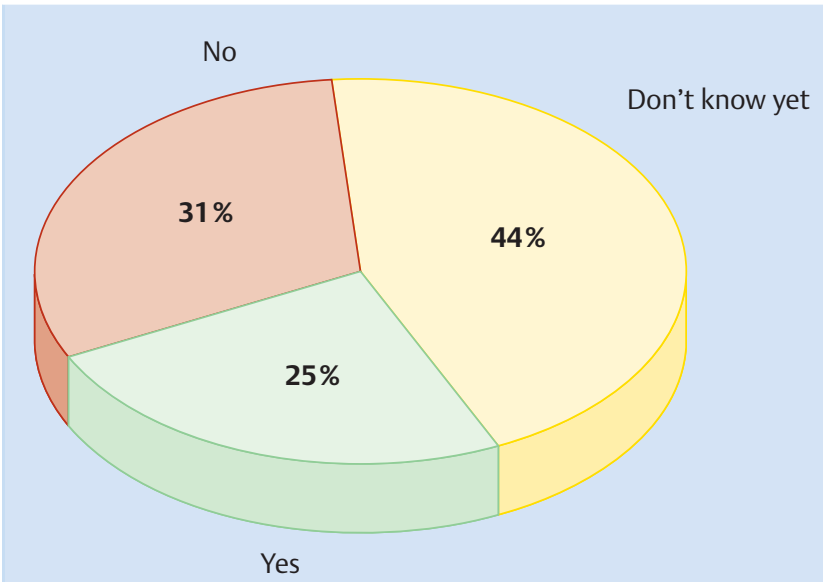

Fig. 2 Are you aiming to work in senology in the future?

Table 1 Overall rating of the quality of senology training according to training facility (facility score). Comparison of university hospitals vs. primary and secondary care facilities $(p=0.064)$ or maximum level care hospitals $(p=0.047)$.

\begin{tabular}{|l|l|}
\hline Training facility & Score $(\varnothing)$ \\
\hline Primary and secondary level hospital & 3.44 \\
\hline Maximum level care hospitals & 3.62 \\
\hline University hospitals & 2.95 \\
\hline Total & $\mathbf{3 . 3 4}$ \\
\hline
\end{tabular}

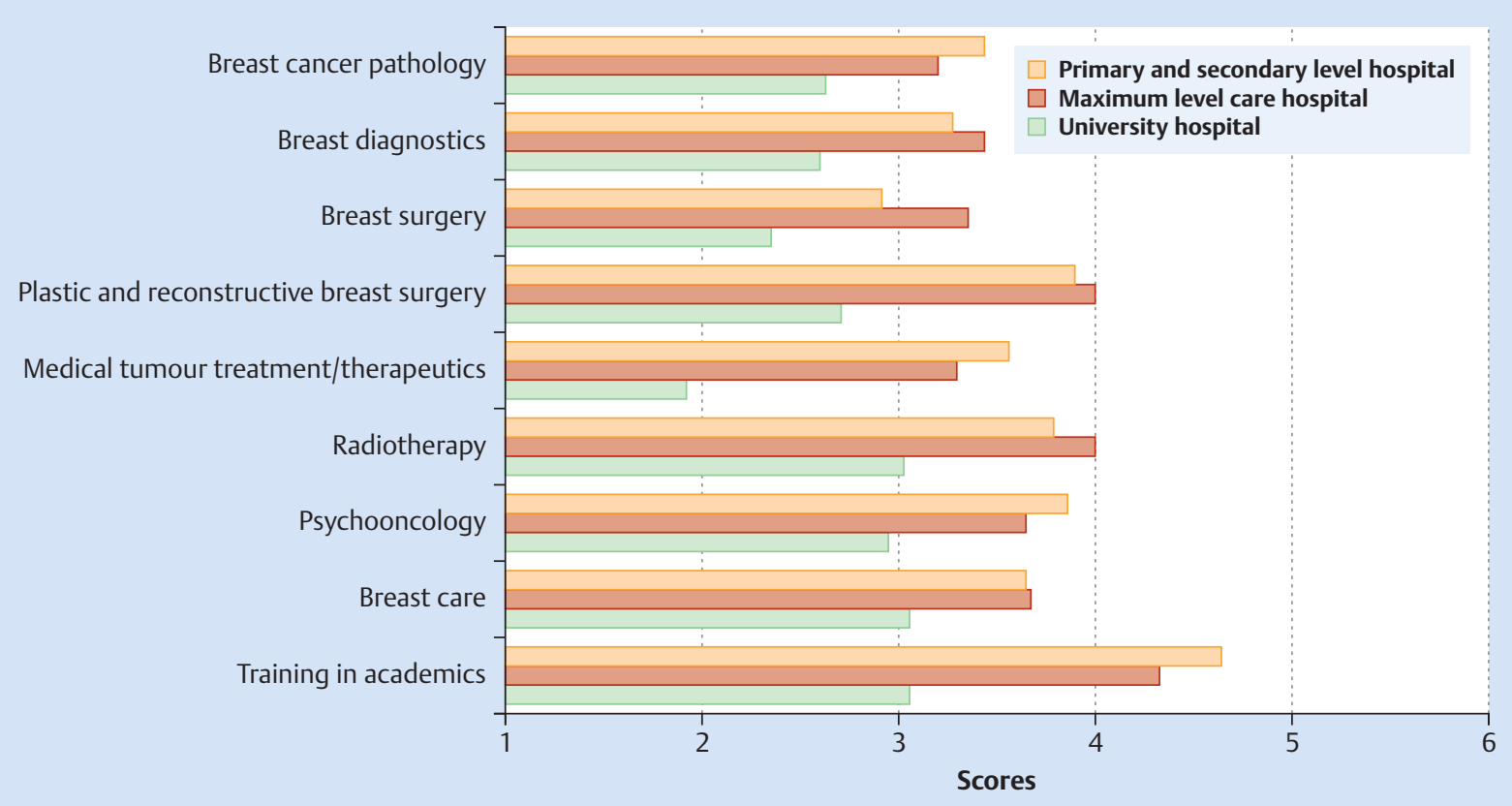

Fig. 3 How do participants rate the quality of further training in the following areas at their training facilities? (score). 


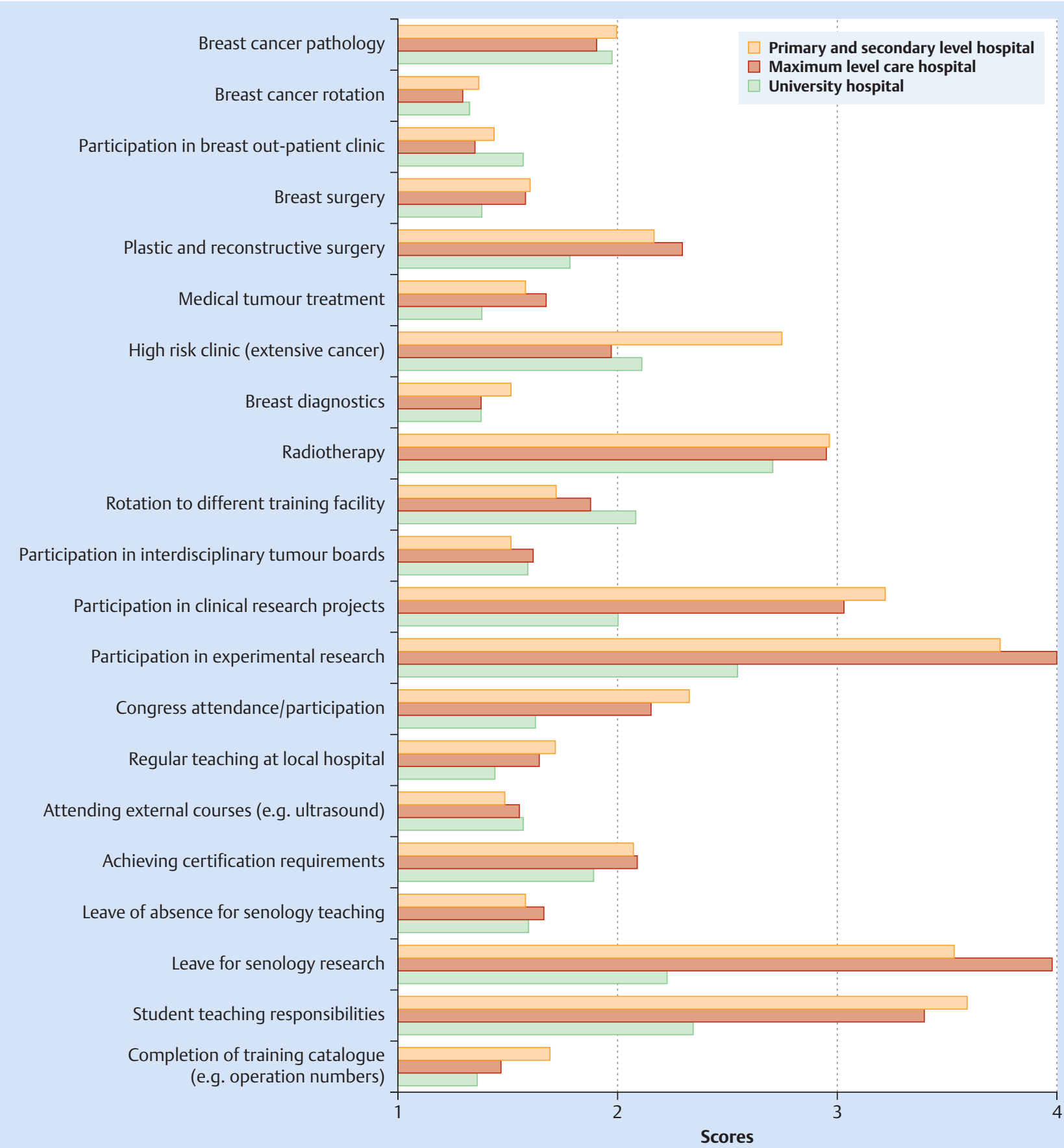

Fig. 4 How important is the following training content to you? Rating scale: $1=$ very important to $6=$ not important at all; not rated $>4$ (score).

Training content: Desire for a fixed rotation through a breast centre and regular teaching Participants were questioned on the necessity of various training contents in order to identify possible areas for improvement (O Fig. 4). All trainees considered a fixed rotation through a breast centre and comprehensive training in breast surgery and investigation of breast disease particularly important, as well as regular structured teaching. The completion of a logbook, which is a general requirement for the specialist qualification, continues to be a source of worry for trainees. Interest in a teaching career (medical education) (university hospitals [2.34] vs. primary and secondary level hospitals [3.59] or maximum level care hospitals
[3.39]) and experimental research (university hospitals [2.54] vs. primary and secondary level hospitals [3.74] or maximum level care hospitals [4.00]) was highest at university hospitals. The difference was significant in each case $(\mathrm{p}<0.001)$.

\section{Possible improvements in training quality}

Finally, the survey evaluated which factors are relevant for good quality training ( $\bullet$ Fig. 5). Trainees saw particular value in a comprehensive system of mentoring. Sufficient time for the imparting of knowledge on the part of those responsible for training was seen as very important. All trainees wanted to be able to accomplish routine clinical tasks within regular working hours. 


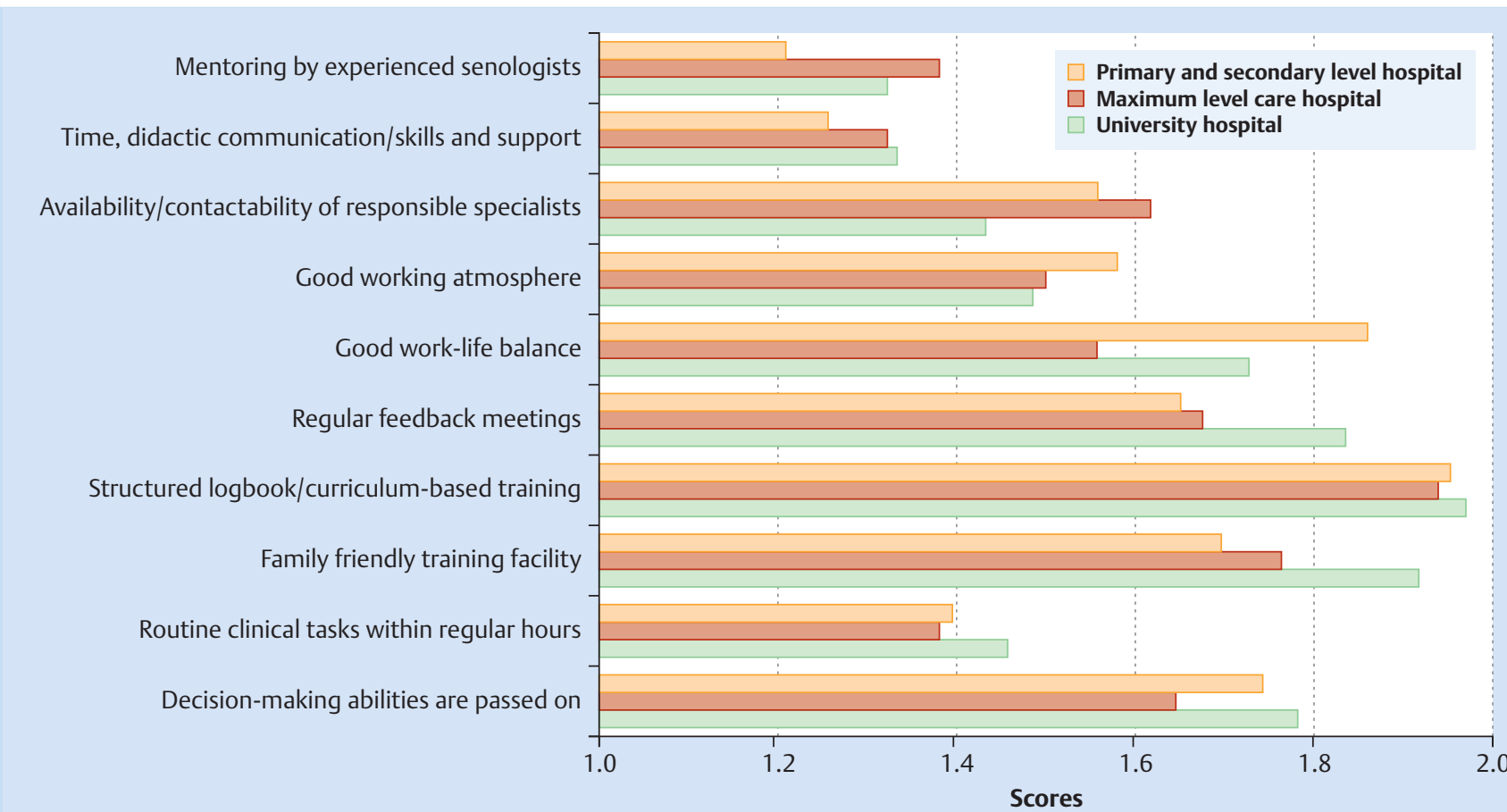

Fig. 5 What do you find important for the quality of training in senology? Rating scale: $1=$ very important to $6=$ not important at all; not rated $>2$ (score).

Structured training was desired at all hospitals. Overall there were no significant differences here between types of training facility.

\section{Discussion}

$\nabla$

This is the first countrywide survey of obstetrics and gynaecology specialist trainees concerning their senology/mastology training. We were able to show that senology is regarded as an integral component of gynaecology. It was found that a predominance of female doctors works in the field, as is also the case in medicine and gynaecology in general $[5,6]$. This increase in female doctors will lead to problems with the number of new doctors coming through in the operative specialities: according to a recent study, women pursue surgical careers more seldom and take up parttime posts more often, which leads to an increased requirement for doctors [7]. In view of the high proportion of out-patients and elective operations, senology certainly offers good chances of scheduled and regulated working hours, and thus a particular opportunity for doctors seeking part-time employment.

In addition, our survey has shown for the first time that there is widespread interest in the field of senology among trainees. The opportunity therefore exists to attract young doctors to senology through good training and thus strengthen the speciality in the long term.

Overall, the quality of currently practiced training was rated as satisfactory, though there is potential for improvement. This is in agreement with the results of an evaluation on training by the German medical council. The data from 2011 produced an average score of 2.54 for the global evaluation of all specialities, trainees rating gynaecology training with a score of 2.60 slightly worse than the national average $[8,9]$.
According to our data scientific training and associated specialities such as pathology and radiotherapy as well as psychooncology appear to be underrepresented in training content/curricula. In this respect the Young Doctors Alliance (das Bündnis JUNGE ÄRZTE) has called for the structured integration of research content into speciality training in order to avert a shortage of new doctors entering academics [10]. This is also true for senology. A funding programme could support interested trainees in becoming acquainted with the field of senology, assisting them academically, building a structured curriculum and making recommendations to departments involved in training. The effects of a structured, evidence-based curriculum for the breast surgery rotation was tested in a prospective study from Phoenix, USA, which showed a significant increase in satisfaction and knowledge among participants [11]. Plichta et al. investigated the influence of surgical assistance at breast operations on tumour free excision margins [12]. It was shown that a continuous learning curve for trainees on the breast surgery rotation can reduce the rate of positive excision margins. Another recent study of American surgical trainees showed that $72 \%$ of essential breast surgery techniques can be learned within the first three years of specialist training [13]. Although these data can only partially be applied to the German system, they do show that the spectrum of senology can be taught at an early stage of specialist training and that young doctors benefit from an intensive training programme. Our study also supports the idea that further training in senology should ideally be in the context of a fixed rotation through a breast centre. The aim should be to offer interested trainees support in their career development early on and assist in developing long-term career goals.

It was shown that senology training is rated best at university hospitals at almost all levels of content. This could be due to the interdisciplinary approach at university hospitals, which, unlike the other facilities evaluated, provides exposure to all areas of se- 
nology. Also most certified breast centres are affiliated to university hospitals and have a bigger team at their disposal [4]. As certified centres they must have e.g. oncology out-patient care, psychooncology expertise and a pathology institute, which all constitute important aspects of training. In this way interaction with complementary specialities, a prerequisite for certification, is assured. This is certainly also good for training. A point of criticism was that tumour board participation, which is compulsory at breast centres, is often not possible in smaller hospitals. Insufficient opportunity to manage senology patients particularly at primary and secondary level hospitals was a further important point. A programme of trainee rotation through different hospitals is a possible solution to this problem of too little exposure to certain training aspects. There are almost certainly significant differences between individual hospitals, both university hospitals and primary/secondary level institutions, so that the results of this survey should not be generalised prematurely; the questionnaire did not assess hospitals individually.

Through purposeful invitation to survey participation via the DGGG Young Forum newsletter we were able to address the target group of specialist trainees directly, achieving a homogeneous study population. The online nature of the survey allowed for anonymity. A disadvantage of the online format in general is possible lack of representivity, since bias can arise e.g. through computer problems. There were no interview drop-outs registered, probably because the questionnaire was short. A low participation rate $(2.8 \%)$ is the main weakness of this study. Positive and negative selection bias can be assumed: on the one hand motivated, on the other, frustrated trainees. The bulk of trainees nationwide did not participate, possibly due to lack of interest in political participation, which is a factor that has been confirmed in other surveys [14]. This is regrettable since such surveys enable active participation in the improvement of training structures.

\section{Conclusion}

\section{$\nabla$}

This is the first baseline survey of current training quality in senology in Germany. Results show that a substantial number of young doctors could potentially enter the speciality field. The subjective experience of training quality varies significantly between types of training facility. These findings could serve as a basis and impetus for improved provision of comprehensive training in senology, thus making the speciality more attractive to future senologists.

Further information at: http://www.dggg.de/junges-forum/

\section{Take home message}

$\nabla$

- There is significant potential for young blood entering speciality training in senology.

- Subjective experience of training quality varies significantly between types of training facility.

- These findings could serve as a basis and impetus for improved provision of comprehensive senology training.

\section{Acknowledgements}

\section{$\nabla$}

We would like to thank all the members of the Young Forum working group for the fruitful discussions towards compilation of the questionnaire, and we thank the DGGG for publicising the survey in the newsletter. In addition we thank all those who participated in the survey.

\section{Conflict of Interest}

$\nabla$

None.

\section{Affiliations}

${ }^{1}$ Uniklinik Köln - Klinik und Poliklinik für Frauenheilkunde und Geburtshilfe, Köln

2 Universitätsfrauenklinik und Poliklinik am Klinikum Südstadt Rostock,

Rostock

3 Universitätsklinikum Erlangen - Frauenklinik, Erlangen

${ }^{4}$ Vinzenzkrankenhaus Hannover - Frauenklinik, Hannover

${ }^{5}$ Vivantes Klinikum Neukölln - Frauenklinik, Berlin

${ }^{6}$ Universitäts-Frauenklinik Heidelberg, Heidelberg

\section{References}

1 Dieterich M, Dieterich H, Nestle-Krämling C et al. [Certification of breast surgeons in Germany-AWO-gyn curriculum in an International comparison]. Geburtsh Frauenheilk 2009; 11: 987-992

2 Wallwiener D. Strategien, Erfolge, Visionen - Bericht des Präsidenten der Deutschen Gesellschaft für Senologie. Senologie 2011; 8: 44-57

3 Online: http://www.senologie.org/deutsche-akademie-fuersenologie; last access: 02.05.2016

4 Brucker SY, Simoes E, Wallwiener D et al. Zertifizierung von Brustzentren. Was haben wir erreicht? Gynäkologische Praxis 2014; 38: 329

5 Bitzinger D, Heberlein A, Theilmeier G. Forschung in der Weiterbildung: Die Generation Y will klare Ansagen über Karrierewege. Dtsch Arztebl 2014; 111: A-442/B-384/C-368

6 Hibbeler B, Korzilius $H$. Arztberuf: Die Medizin wird weiblich. Dtsch Arztebl 2008; 105: A-609/B-539/C-527

7 Riepen T, Mobus V, Kullmer U et al. Male and female physicians in hospital gynaecology departments - analysis of the impact of "feminisation" from the viewpoint of medical directors. Geburtsh Frauenheilk 2013; 73: 53-58

8 Korzilius $\mathrm{H}$. Evaluation der Weiterbildung: Im Ergebnis eine gute Zwei minus. Dtsch Arztebl 2011; 108: A-2694/B-2250/C-2222

9 Online: http://www.evaluation-weiterbildung.de/ergebnisse.html; last access: 02.05.2016

10 Online: https://jungeaerzte.wordpress.com/pressemitteilungenveroffentlichungen/; last access: 02.05.2016

11 Komenaka IK, Heberer MA, O'Neill PJ et al. The effect of an evidencebased medicine curriculum on breast cancer knowledge and satisfaction of surgical residents. J Surg Educ 2015; 72: 717-725

12 Plichta JK, Perez CB, He E et al. Does practice make perfect? Resident experience with breast surgery influences excision adequacy. Am J Surg 2015; 209: 547-551

13 Conway RG, Bartlett EK, Hoffman RL et al. Residents' experience in breast cancer care. J Surg Educ 2015; 72: 1233-1239

14 Knieper C, Ramsauer B, Hancke K et al. "Pregnant and operating": evaluation of a Germany-wide survey among female gynaecologists and surgeons. Geburtsh Frauenheilk 2014; 74: 875-880 